\title{
THE IMPACT OF EARLY SEASON INSECTICIDES ON BIOLOGICAL CONTROL OF APPLE LEAFCURLING MIDGE (DASINEURA MALI)
}

\author{
P.W. SHAW ${ }^{1}$, D.R. WALLIS ${ }^{1}$ and D.J. ROGERS ${ }^{2}$ \\ ${ }^{1}$ HortResearch, PO Box 220, Motueka, New Zealand \\ ${ }^{2}$ HortResearch, Private Bag 1401, Havelock North, New Zealand \\ Corresponding author: pshaw@hortresearch.co.nz
}

\begin{abstract}
The fate of apple leafcurling midge (ALCM, Dasineura mali) egg batches was monitored in spring 2003 at two apple orchards in Riwaka near Motueka. Orchard A had received pre-bloom insecticide applications of chlorpyrifos and carbaryl for fruit thinning each season since 2000 . Orchard B substituted these chemicals with the selective insecticide buprofezin and used benzyladenine for fruit thinning over the same period. Predation and parasitism of ALCM eggs at orchard B resulted in lower survival of larvae and less damage to shoots compared to orchard A. Ninety percent of ALCM larvae at orchard B were parasitised by Platygaster demades compared with only $3 \%$ at orchard A. Heavy infestation of shoots by second generation midge larvae at orchard A resulted in premature termination of $69 \%$ of growing shoot tips. These results suggest that non-selective early season insecticides used in pipfruit spray programmes may disrupt biological control of ALCM.
\end{abstract}

Keywords: apple leafcurling midge, insecticides, biological control.

\section{INTRODUCTION}

Apple leafcurling midge (Dasineura mali Keiffer) (ALCM) has been present in New Zealand since 1950 but was largely considered a minor pest controlled by insecticides applied for other insect pests (Tomkins et al. 2000). During the mid 1980s ALCM populations increased considerably in apple orchards throughout New Zealand leading to a change in pest status (Tomkins et al. 1994). ALCM larvae can damage the leaves, flowers and fruitlets of apple trees, and pupal cocoons may contaminate fruit leading to significant quarantine problems. Larvae feed mainly inside tight leaf rolls formed when emerging leaves fail to open due to midge infestation. Heavily infested leaves may drop prematurely and developing shoots can be stunted or killed with damage to young trees being particularly severe (Lowe 1993). Management of ALCM with insecticides relies on spring application(s) of diazinon applied either to the soil to control emerging adults and/or foliar sprays targeted against midge eggs (Burnip et al.1998). However, diazinon is rarely used by pipfruit growers for ALCM control on mature trees. The three broadspectrum insecticides (diazinon, chlorpyrifos and carbaryl) still included in the New Zealand IFP guidelines for pipfruit (Anon. 1998) can be disruptive to important natural enemies in orchards (Bradley et al. 1997; Shaw et al. 1997; Burnip et al. 1998). The use of broad-spectrum insecticides limits the development of a more sustainable pipfruit production programme (Wearing 1997).

The adult Platygaster demades parasitises ALCM eggs. The embryo develops slowly in the host larva and the adult wasp emerges just prior to ALCM pupation (Tomkins et al. 2000). Todd (1959) reported the presence of $P$. demades during the first generation of ALCM and in generations three and five. However, he noted $P$. demades was largely absent from the second generation, which causes the most damage to trees. Tomkins et al. (2000) found a single soil treatment with diazinon reduced populations of ALCM and $P$. demades. 
This study examined ALCM populations at two orchards. In one orchard broadspectrum insecticides were used for the three years prior to this study, whereas more selective products were used at the other orchard. The impact of these spray options on biological control of ALCM is discussed.

\section{METHODS}

The study was conducted in mature Braeburn blocks (M793 rootstock) at two orchards near Motueka. An assessment of 200 shoots in 2001 at each orchard indicated there were similar levels of ALCM infestation. Prior to the 2000-2001 fruit season chlorpyrifos and carbaryl were used at both orchards. For the past three seasons orchard A received single pre-bloom applications of mineral oil and chlorpyrifos in late August followed by carbaryl in early November. Orchard B was sprayed with mineral oil and buprofezin in late August throughout the same period and with benzyladenine in November 2000 and 2001. No diazinon was used at either orchard during the three-year period. Thirty developing shoots, each infested with a single freshly laid ALCM egg batch, were tagged at each orchard on 10 October 2002. This time corresponded to peak egg laying, which was the beginning of the first generation of ALCM. The fate of these eggs and damage to shoots was monitored regularly between $14-28$ October 2002 . The cumulative number of tagged shoots with new leaf rolls and visibly damaged egg batches (assumed to indicate predation) were recorded on each observation date. On each of the tagged shoots, the number of rolled leaves per shoot tip, the number of rolls on infested leaves and the length of rolls was recorded on 7 November 2002 to indicate the degree of ALCM infestation at each orchard. Thirty infested leaves from tagged shoot tips at each orchard were collected and 40 mature ALCM larvae were extracted from orchard B and 100 larvae were extracted from orchard A. These larvae were dissected and examined with a microscope on 7 November 2002 to determine the percentage parasitised by P. demades. On 6 January 2003, one hundred shoot tips (10 from 10 trees) at each orchard were monitored to assess infestation by the second generation of ALCM. The percentage of infested shoot tips was recorded and shoot tips were examined and assessed to be either still growing, terminated naturally or terminated prematurely as a result of high ALCM infestation.

The standard errors for data presented in Figure 1 were derived based on the binomial distribution. The Poisson distribution was used to analyse data on the number of rolled leaves per infested shoot and mean roll length data was log-transformed. No distribution was found to satisfactorily approximate the number of rolls per infested leaf so no standard errors were calculated for this data in Table 1.

\section{RESULTS AND DISCUSSION}

Monitoring of 200 shoots at both orchards in 2001 showed that second generation ALCM infestation at both sites was similar, with $78 \%$ infested shoots at orchard A and 93\% at orchard B (P.W. Shaw, unpubl. data).

Fifty percent of the egg batches $(n=30)$ on tagged shoots at orchard B showed signs of predation (damaged and dried egg remains) while none of the egg batches at orchard A showed similar signs (Fig. 1). A large red predatory mite (Bdellidae) was observed feeding on an ALCM egg batch at orchard B, but the identity of other potential predators of midge eggs was not established. The number of tagged shoots with newly rolled leaves increased more quickly and ultimately was higher at orchard A (28/30) compared to orchard B (19/30) (Fig. 1).

The mean number of rolled leaves per shoot tip, the mean number of rolls on infested leaves and the mean length of leaf rolls were greater at orchard A (Table 1). These results suggest more larvae survived from the tagged egg batches at orchard A compared with orchard B. Predation and parasitism of eggs and predation of surviving larvae is a probable explanation for differences in first and second generation larval infestation levels at the two orchards. During the monitoring period, large numbers of a predatory bug, Sejanus albisignata, were seen at orchard B but none were seen at the other site. 
Sejanus albisignata is often seen in ALCM leaf rolls and has been observed feeding on ALCM eggs (A.R. Gibb, unpubl. data). Shaw et al. (1997) reported lower trap catches of $S$. albisignata in blocks treated with chlorpyrifos compared to buprofezin.

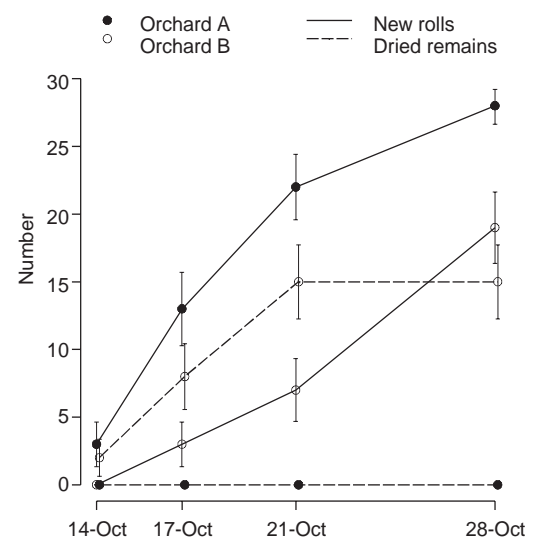

FIGURE 1: The cumulative number of shoots with new ALCM-infested leaf rolls and egg batches with dried remains found on thirty tagged shoots at two orchards. Vertical bars represent one standard error each way.

On 7 November 2002, $90 \%$ of mature first generation larvae at orchard B were found to be parasitised by $P$. demades compared to 3\% at orchard A. Shaw \& Rogers (2002) reported a higher percentage of shoots infested with ALCM and less parasitism of ALCM by $P$. demades in blocks treated with chlorpyrifos compared to buprofezin. The timing of the chlorpyrifos application in late August is just prior to the first emergence of overwintering $P$. demades adults from the soil (Tomkins et al. 2000). Therefore this application is unlikely to affect adults directly. However, spray residues on the soil and shoot tips may be toxic to adults as they emerge from the soil and while they are parasitising ALCM egg batches on shoot tips. Carbaryl applied for fruit thinning in November may also be toxic to natural enemies including $P$. demades and $S$. albisignata that are present in the orchard at this time.

TABLE 1: Measurements indicating the level of ALCM infestation on 30 tagged shoots in three categories at each orchard on 7 November 2002.

\begin{tabular}{lccccc}
\hline & \multicolumn{2}{c}{ Orchard A } & & \multicolumn{2}{c}{ Orchard B } \\
\cline { 2 - 3 } & Mean & S.E. & & Mean & S.E. \\
\hline No. of rolled leaves per shoot & 2.67 & $(0.30)$ & & 1.07 & $(0.19)$ \\
No. of rolls per infested leaf & 1.27 & - & & 1.11 & - \\
Mean log roll length $(\mathrm{mm}){ }^{1}$ & 2.84 & $(0.054)$ & & 2.40 & $(0.094)$ \\
\hline
\end{tabular}

${ }^{1}$ Back-transformed means were 17.1 and 11.1 for Orchards A and B respectively.

The low level of parasitism and apparent lack of predation of the first generation of ALCM at orchard A contributed to increased shoot tip damage by second generation larvae at this site. At orchard A, 69 shoots were terminated by midge damage and 9 shoots were terminated naturally compared to only 1 shoot terminated by midge and 51 terminated naturally at orchard $\mathrm{B}\left(\mathrm{X}^{2}=105.1 ; \mathrm{P}<0.001\right.$; Table 2$)$. 
TABLE 2: The number of shoots out of a total of 100 that were either terminated naturally or terminated by ALCM infestation and the number still growing on 6 January 2003 at each orchard.

\begin{tabular}{lccc}
\hline & Terminated naturally & Terminated by ALCM & Growing \\
\hline Orchard A & 9 & 69 & 22 \\
Orchard B & 51 & 1 & 48 \\
\hline
\end{tabular}

\section{CONCLUSION}

The absence of broad-spectrum insecticides at orchard B over three seasons was the probable cause of higher levels of parasitism and predation that were associated with lower levels of ALCM infestation. However, more extensive studies on a larger number of orchards are required to verify these results and establish whether biological control can contain populations of ALCM or reduce them further.

\section{ACKNOWLEDGEMENTS}

We wish to thank Peter Alspach for his advice on statistical analyses. N.Z. Pipfruit Ltd and the New Zealand Foundation for Research, Science and Technology provided funding.

\section{REFERENCES}

Anon. 1998: New Zealand Integrated Fruit Production - Pipfruit Manual. Published by ENZAFRUIT New Zealand (International), Hastings.

Bradley, S.J.; Murrell, V.C.; Shaw, P.W.; Walker, J.T.S. 1997: Effects of orchard pesticides on Aphelinus mali, the woolly apple aphid parasitoid. Proc. 50th N.Z. Plant Prot. Conf:: 218-212.

Burnip, G.M.; Gibb, A.R.; Suckling, D.M. 1998: Target and non-target impacts from diazinon applied against Dasineura mali in a Canterbury apple orchard. Proc. 51st N.Z. Plant Prot. Conf:: 143-147.

Lowe, S. 1993. Apple leafcurling midge. Pipmark technical bulletin, New Zealand apple and pear marketing board. $5 \mathrm{p}$.

Shaw, P.W.; Bradley, S.J.; Walker, J.T.S. 1997: The impact of early season insecticides in an integrated fruit production programme on apple. Proc. 50th N.Z. Plant Prot. Conf:: 283-287.

Shaw, P.W.; Rogers, D.J. 2002: Assessment of apple leafcurling midge (ALCM) and woolly apple aphid (WAA) in Integrated Fruit Production (IFP) and Organic Fruit Production (OFP) programmes. Client Report to Pipfruit N.Z. Ltd. No. 2003/90, HortResearch. 26 pp.

Todd, D.H. 1959: The apple leaf-curling midge, Dasyneura mali Kieffer, seasonal history, varietal susceptibility and parasitism 1955-58. N.Z. J. Agric. Res. 2:859-869.

Tomkins, A.R.; Wilson, D.J.; Hutchings, S.O.; June, S. 1994: A survey of apple leafcurling midge (Dasyneura mali) management in Waikato orchards. Proc. $47^{\text {th }}$ N.Z. Plant Prot. Conf:: 364-349.

Tomkins, A.R.; Wilson, D.J.; Thomson, C.; Bradley, S.; Cole, L.; Shaw, P.; Gibb, A.; Suckling, D.M.; Marshall, R.; Wearing, C.H. 2000: Emergence of apple leafcurling midge (Dasineura mali) and its parasitoid (Platygaster demades). Proc. 53rd N.Z. Plant Prot. Conf:: 179- 184.

Wearing, C.H. 1997: Indicators of sustainable pest management in orchard production systems. Proc. 50th N.Z. Plant Prot. Conf.: 506-513. 